\section{The Framework Convention on Tobacco Control: promising start, uncertain future}

\section{R Hammond, M Assunta}

\section{Will the first global health treaty be allowed to live up to expectations?}

O n 21 May 2003, to the sound of thunderous applause, the 192 member states of the 56th World Health Assembly unanimously adopted the first global health treaty, the Framework Convention on Tobacco Control (FCTC). A groundbreaking treaty which aims to curb tobacco use worldwide, the FCTC holds the potential to help reverse the global tobacco epidemic, particularly in low income countries. With tobacco projected to claim a billion lives this century, ${ }^{1}$ the stakes could hardly be higher. According to the World Bank, tobacco is responsible for half the diseases and deaths in developing countries. $^{2}$

Although described by the tobacco industry as a "developed world obsession being foisted on the developing world"* , it was in fact developing countries which saved the FCTC from being gutted by a handful of developed countries which have no intention of ever implementing most of its provisions. Unlike other treaties, where developed countries dominate the debate, developing countries were vocal, spirited, and led the charge for most of the progressive provisions.

The final agreement, reached after nearly four years of diplomatic manoeuvering and at times acrimonious negotiations, provides the basic tools for countries to enact comprehensive tobacco control legislation. Key obligations in the treaty encourage countries to:

- enact comprehensive bans on tobacco advertising, promotion, and sponsorship

- obligate the placement of rotating health warnings on tobacco packaging that cover at least 30\% (but ideally $50 \%$ or more) of the principal display areas and can include pictures or pictograms

- ban the use of misleading and deceptive terms such as "light" and "mild"

* Martin Broughton, quoted on "BAT profits nearly double," BBC Online, 7 March 2000.
- protect citizens from exposure to tobacco smoke in workplaces, public transport, and indoor public places

- combat smuggling, including the placing of final destination markings on packs

- increase tobacco taxes. ${ }^{3}$

Although laudable, few of these measures were made obligatory, a direct result of intense pressure from a handful of countries, particularly the USA, Japan, and Germany. This means that in many cases it will be up to individual countries to decide how far to go in implementing the treaty. Fortunately, the FCTC explicitly encourages countries to implement measures that are stronger than the minimum standards required by the treaty.

\section{ENTHUSIASM RUNNING HIGH}

Enthusiasm for the treaty is running high. Within the first week that the FCTC was open for signature, 41 countries from all six World Health Organization regions, as well as the European Community, had officially signed the treaty. The next step will be to get these countries to ratify. Forty countries need to ratify the treaty before it enters into force, after which protocol negotiations can proceed (on smuggling and crossborder advertising, for example), and a subsidiary body will begin meeting to review country compliance and provide technical (and possibly) financial assistance. Advocates are hoping that by next year's World Health Assembly, the requisite 40 countries will have ratified the FCTC to bring it too life.†

However long it eventually takes to bring it into force, the FCTC process has already had a major impact in advancing national and global tobacco control efforts. The negotiations encouraged many countries to re-examine their domestic tobacco policies and begin to

†For a current list of countries that have signed and/or ratified, go to www.fctc.org pay attention to those cross-border aspects, such as advertising and smuggling, which have long been neglected.

\section{NGO COMMUNITY}

In addition, the negotiations provided an opportunity for negotiators-many of whom represented tobacco control units within their health ministries-to exchange information with each other on global best practices and tobacco industry tactics. The non-governmental organisation (NGO) community-which maintained an active presence at all of the negotiating sessions-assisted in this capacity by organising issue briefings for delegates and distributing a daily newsletter. These helped cut through the diplomatic niceties, discouraging the negotiators from embracing "feel good" measures favoured by the tobacco industry, and meting out public shame to recalcitrant countries through the daily giving of a "dirty ashtray award".

NGOs also benefited from the negotiations, both through their increased contacts with governments and the sharing of information among a growing number of NGOs grouped under the umbrella of the Framework Convention Alliance, a coalition of more than 180 groups from $\begin{array}{llll}\text { over } & 70 \quad \text { countries (www. }\end{array}$ fctc.org). This highlights the reality that in many poor countries it is NGOs which are in the forefront of tobacco control efforts. The FCTC helped to build the confidence and knowledge of these non-state actors and brought new groups into the tobacco control movement, such as environmental, human rights, and womens' organisations. The negotiations process also helped spur the formation of national coalitions in countries such as Bangladesh, India, and the Philippines, a development which bodes well for efforts to move governments quickly along the road to ratification and implementation.

The treaty should prove particularly useful to countries that have yet to enact stringent tobacco control legislation. Countries such as Cambodia and Indonesia, with male smoking prevalence rates of over $60 \%$, ${ }^{4}$ currently have weak tobacco control measures. The momentum of the treaty not only empowers governments to act, but gives them little excuse not to.

So far, the global tobacco industry has been relatively mute about the final outcome of the negotiations. Most likely it is gearing up for fights at the national level where it believes it will have more leverage. It will certainly try to ensure that implementing legislation is weak and full of loopholes and will continue to promote self-regulation as the answer to the tobacco pandemic.

It remains to be seen whether the political will can be generated to ensure that implementing legislation in countries encapsulates the maximum measures contemplated in the FCTC (for 
example, $50 \%$ pack warnings rather than $30 \%$, bans rather than restrictions on public smoking, etc). It also is unclear how the provisions of the FCTC would withstand trade based challenges through the World Trade Organization. The relationship between the FCTC provisions and international trade agreements-one of the most contentious issues in the negotiations-was left ambiguous in the final document, again a result of developed country pressure.

The end of the FCTC negotiations marks a defining moment in the effort to combat the tobacco epidemic. Without swift and concerted action to bring the FCTC into force and ensure that countries implement it to the fullest, there is the danger that the treaty will end up as just another well intentioned resolution. Too many lives are at stake to allow that to happen.

Tobacco Control 2003;12:241-242

\section{Authors' affiliations}

R Hammond, Campaign for Tobacco Free Kids, San Francisco, California, USA

M Assunta, University of Sydney, Sydney, New South Wales, Australia
Correspondence to: Mary Assunta, University of Sydney, Sydney, NSW 2006, Australia; marya@health.usyd.edu.au

\section{REFERENCES}

1 Proctor RN. Tobacco and the global lung cancer epidemic. Nature Reviews Cancer 2001;1:82-6.

2 Brigden LW, de Beyer J, eds. Tobacco control policy: strategies, success, and setbacks. The World Bank, May 2003.

3 Framework Convention for Tobacco Control. Full text can be found at: http://www.who.int/gb/fctc/PDF/inb6/ einb65.pdf

4 Corrao MA Guindon GE, Sharma N, et al, eds. Tobacco control country profiles. Atlanta, Georgia: American Cancer Society, 2000.

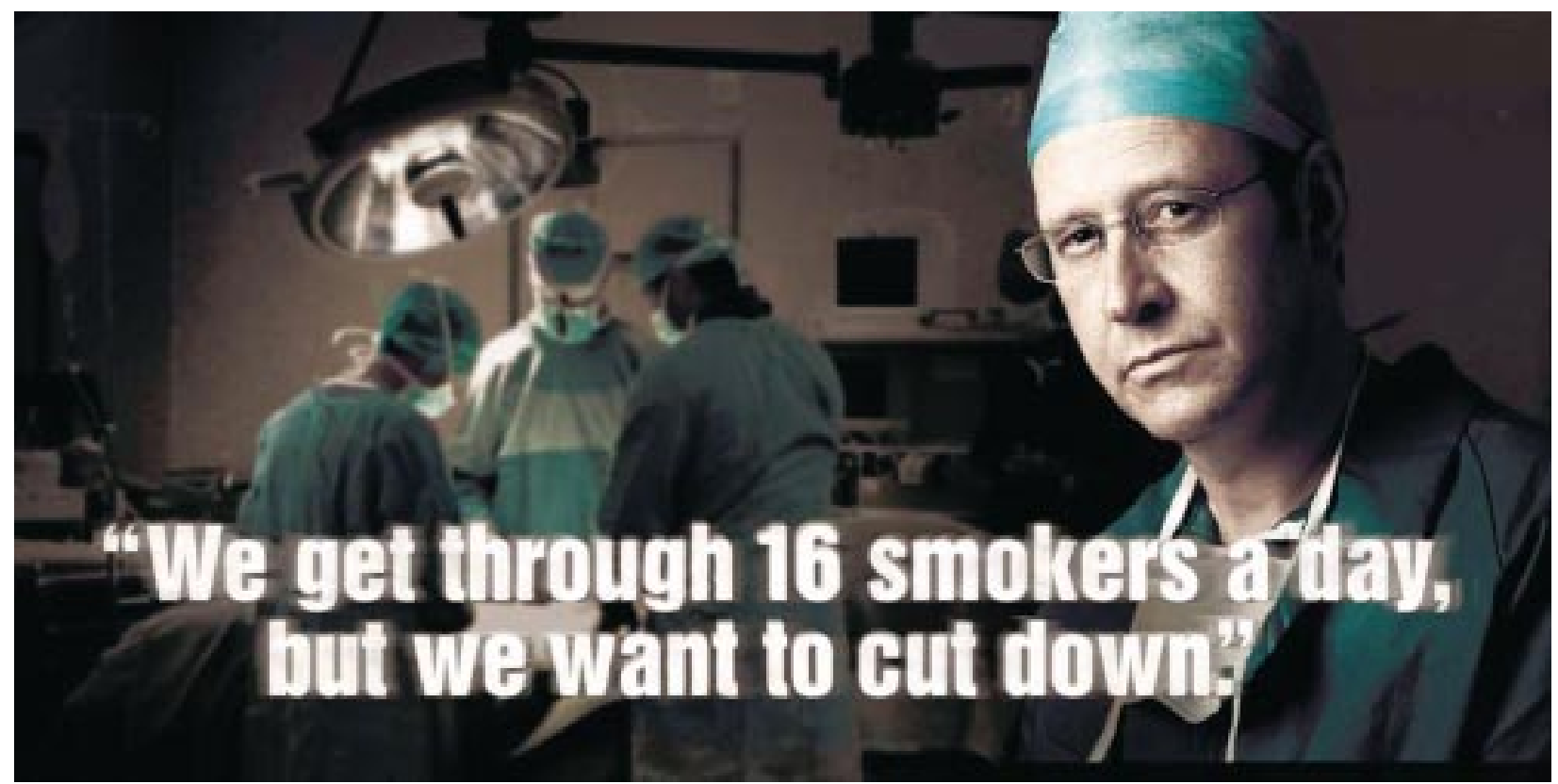

Make Smoking History billboard unveiled on 23 April in WA, Australia; Mr Mark Newman and his surgical team, who operate on lung cancer patients. 